\title{
Evaluation of sodium lauryl sulfate for the development of cow-side mastitis screening test
}

\author{
Nobonita Sarker Tanni ${ }^{1}$, Md. Shafiul Islam ${ }^{1,2}$ (D) Mojahidul Kabirit, ${ }^{1,}$, Mst. Sonia Parvin ${ }^{1}$, \\ Md. Amimul Ehsan ${ }^{1}$ iD and Md. Taohidul Islam ${ }^{1}$ (D)
}

\begin{abstract}
1. Population Medicine and AMR Laboratory, Department of Medicine, Faculty of Veterinary Science, Bangladesh Agricultural University, Mymensingh-2202, Bangladesh; 2. Poultry and Livestock Program (Ultra Poor Graduation

Program), BRAC, Barishal, Bangladesh; 3. Department of Livestock Services, Farmgate, Dhaka, Bangladesh. Corresponding author: Md. Taohidul Islam, e-mail: taohid@bau.edu.bd

Co-authors: NST: nobonitabau@gmail.com, MSI: shafiul.med@gmail.com, MK: mojahidulkabir132@gmail.com, MSP: soniaparvin@bau.edu.bd, MAE: amimul.med@bau.edu.bd

Received: 09-04-2021, Accepted: 29-07-2021, Published online: 31-08-2021
\end{abstract}

doi: www.doi.org/10.14202/vetworld.2021.2290-2295 How to cite this article: Tanni NS, Islam MS, Kabir M, Parvin MS, Ehsan MA, Islam MT (2021) Evaluation of sodium lauryl sulfate for the development of cow-side mastitis screening test, Veterinary World, 14(8): 2290-2295.

\begin{abstract}
Background and Aim: Subclinical mastitis (SCM) is an economically important disease for dairy cattle worldwide; therefore, regular screening is imperative to detect SCM at an early stage so as to control it. The study was conducted to compare the test characteristics of sodium lauryl sulfate (SLS) as a test reagent to detect SCM in dairy cows.

Materials and Methods: First, 106 milk samples of dairy cows were subjected to available indirect screening tests (white side test [WST], surf field mastitis test, Leucocytest, and Immucell) considering somatic cell count (SCC) as gold standard test. Then 273 milk samples were allowed to react with different concentrations of SLS with or without sodium hydroxide $(\mathrm{NaOH})$ and indicators (bromothymol blue $[\mathrm{BTB}]$ and bromocresol purple $[\mathrm{BCP}]$ ).
\end{abstract}

Results: SLS with or without $\mathrm{NaOH}$ yielded best reaction with the milk samples similar to Leucocytest. It was observed that the reaction of milk samples with SLS added with indicators (BTB and BCP) was easier to visualize than without indicators. SLS $3 \%+\mathrm{NaOH} 1.5 \%$ with BTB and SLS $2 \%$ with BCP had high sensitivity, specificity, and substantial agreement with SCC. The area under the receiver operating characteristics curve of SLS $2 \%$ with BCP and SLS 3\%+NaOH 1.5\% with BTB was 0.917 and 0.875 , respectively.

Conclusion: It may be concluded that SLS 3\%+NaOH $1.5 \%$ with BTB and SLS $2 \%$ with BCP may be the potential reagents for the development of an effective cow-side test to detect SCM, as the main ingredient SLS is considerably cheap and readily available in developing countries.

Keywords: bovine subclinical mastitis, dairy cows, screening test, sensitivity, sodium lauryl sulfate, specificity.

\section{Introduction}

Mastitis is one of the most prevalent and costly diseases of dairy cows [1]. It occurs in two forms, clinical and subclinical mastitis (SCM) [1]. SCM is the foremost production disease of dairy cows, which can directly or indirectly affect the economy of the farmers globally, including in developing countries [2-4]. Earlier reports indicate that the cost of SCM is often greater than that of clinical mastitis $[5,6]$. SCM is the inflammation of the mammary gland that does not create any visible changes in the milk or of the udder but the quality and quantity of the milk is highly altered [1]. Both clinical and subclinical forms of mastitis have been considered as the major constraints for the development of the dairy industry in Bangladesh [7]. SCM in dairy cows is important because it (a) is $15-40$ times

Copyright: Tanni, et al. Open Access. This article is distributed under the terms of the Creative Commons Attribution 4.0 International License (http://creativecommons.org/licenses/by/4.0/), which permits unrestricted use, distribution, and reproduction in any medium, provided you give appropriate credit to the original author(s) and the source, provide a link to the Creative Commons license, and indicate if changes were made. The Creative Commons Public Domain Dedication waiver (http://creativecommons.org/ publicdomain/zero/1.0/) applies to the data made available in this article, unless otherwise stated. more prevalent than the clinical form, (b) usually precedes the clinical form, (c) is of long duration, (d) is often undetected, (e) reduces milk production, (f) adversely affects milk quality, and (g) serves as reservoirs for the spread of the infection to other cows in the herd $[8,9]$. SCM causes $1.2-33 \%$ milk production losses in affected quarters; however, this loss per farm ranges from $1.3 \%$ to $13.5 \%[10,11]$. The reduction in milk production attributed to SCM accounts for $32-70 \%$ of the total losses [5,12]. Like other countries, SCM is also a major problem for dairy cows in Bangladesh $[13,14]$. The prevalence of bovine SCM in Bangladesh is $20.2 \%$ [13]. The annual economic losses that occur due to reduced milk production caused by SCM in Bangladesh have been estimated to be Taka 122.6 million (US \$ 2.11 million) [7].

Early detection of SCM is the key component of a mastitis control program [15]. SCM is not a problem of individual cow rather a problem at the dairy herd level [6]. Therefore, it is essential to test the dairy herd of cows periodically for the screening of SCM [14]. According to the International Dairy Federation recommendations, microbiological status of the quarters and the somatic cell count (SCC) are the most 
common tests to detect the changes in the milk due to inflammatory process [16]. Although bacteriological culture of milk samples is considered as the gold standard method to identify intramammary infection (IMI) it does not provide a measure of the degree of inflammation associated with the infection [17]. Since SCM implies inflammation within the udder, but not necessarily infection, the inflammatory reaction due to SCM can be identified by an elevated SCC, a direct screening test [14]. Besides, the SCC is considered as a useful predictor of IMI and an important component of milk to assess the milk quality, hygiene of the herds, and mastitis control program [18-21]. SCC using an automatic counting machine is considered a more accurate direct screening test $[22,23]$. However, it is expensive and not feasible at the field level to be used by the farmers in the context of Bangladesh. There are some indirect cow-side tests to detect SCM at the field level, such as California mastitis test (CMT), white side test (WST), and surf field mastitis test (SFMT) $[16,24,25]$. Among all the indirect screening tests, CMT has been considered as the most sensitive and specific screening test $[26,27]$. The positive reaction of CMT depends on the concentration of somatic cells in the milk [28]. However, in the context of Bangladesh, it is not available whenever needed and is somewhat expensive. The reagent (Sodium alkyl aryl sulfonate) used in the CMT as the leading component is also not readily available in Bangladesh. The ingredients of other tests such as WST and SFMT are available and cheap. However, their sensitivity $(\mathrm{Se})$ and specificity $(S p)$ are lower compared to CMT $[25,29]$. The main component used in CMT (Sodium alkyl aryl sulfonate) is an anionic surfactant which decreases surface tension, changes the structure and conductivity of cell membrane and nucleus, interferes osmotic balance, block oxidization and stimulate proteolytic enzymes, and increase milk viscosity [30]. Like sodium alkyl aryl sulfonate, sodium lauryl sulfate (SLS) may be another potential anionic surfactant with similar functions of sodium alkyl aryl sulfonate to detect SCM [31], which is easily available and cheap.

The study was conducted to compare the test characteristics of SLS as a test reagent to detect SCM in dairy cows.

\section{Materials and Methods}

\section{Ethical approval and informed consent}

Ethical approval was not required for this study because animal experimentation was not done. During milk sample collection, none of the cows were harmed. However, informed written consent was obtained from the owner of the cows to collect milk samples and data. Furthermore, the study protocol was approved by the board of studies of the department, and the Committee for Advanced Studies and Research of the university.

\section{Study period and location \\ The study was conducted from February to May 2018. Study cows were selected from}

Mymensingh Sadar Upazila, and the laboratory works were conducted in the Population Medicine and AMR Laboratory of the Department of Medicine, Bangladesh Agricultural University, Mymensingh.

\section{Collection and transportation of milk samples}

Three hundred and seventy nine milk samples were collected on several occasions from apparently healthy crossbred dairy cows (Friesian $\times$ Indigenous and Sahiwal $\times$ Indigenous) from smallholder dairy farms of Mymensingh Sadar Upazila. The farms mainly practiced zero grazing. The cows were provided with green grasses such as Napier, roadside grass, and seasonal maize. However, cows were given free access to paddy straw as roughage. Besides, most of the cows were offered varying amounts of concentrates such as rice bran, wheat bran, and occasionally chickpea bran. Most of the farms had the brick floor. The practice of manure removal was on a daily basis. Hand milking was practiced in all the farms. Pre- or post-milking teat dipping was not practiced in any of the farms. Milk samples from cows at $1^{\text {st }}$ week of lactation were excluded due to the presence of physiologically high concentration of somatic cells in milk during this period, which may affect the results of indirect screening tests. Grossly, dirty teats and udders were thoroughly washed, dried, and soaked with $70 \%$ ethanol immediately before collection of samples. Three or four streams of milk were discarded to minimize the chance of contamination. Approximately $15 \mathrm{~mL}$ of milk was collected from each quarter in a sterilized falcon tube and kept in a cooler box. Then, the samples were transported to the laboratory within 2-3 h, and screening tests and SCC were performed on the same day.

\section{Study description}

Initially, 106 milk samples were tested with four existing indirect screening tests (WST, SFMT, Leucocytest, and Immucell) and gold standard test (SCC). Among them, the Leucocytest with high $\mathrm{Se}$ was used in the next step. Later, 273 samples were tested with anionic surfactant (SLS) of different concentrations with or without indicators and Lleucocytest. In both steps, SCC was used as gold standard test. All the samples were tested by the first author, who is a skilled registered veterinarian.

\section{Indirect screening tests for SCM}

Leucocytest

The test was conducted as per the manufacturer's instruction (Synbiotics Corporation-2, rue Alexander Fleming-69007 Lyon, France). Briefly, $2.0 \mathrm{~mL}$ of quarter milk sample was mixed with an equal volume of reagent in a paddle. The mixing was accomplished by the gentle circular motion of the paddle in a horizontal plane for few seconds, and the changes in milk fluidity and viscosity were observed. The results were interpreted as 0 (negative), 1+ (weak positive), 2+ (distinct positive), and $3+$ (strong positive). 


\section{Immucell (Coburn Company, USA)}

To make working solution, CMT concentrate was added to the lower line marked on a dispensing bottle, and then water was added to fill the level line marked at top of the dispensing bottle. Milk samples were taken into four cups of a paddle, and then the paddle was tilted until milk was halfway between the inner and outer circles. CMT working solution was added into each cup slowly. In horizontal position, the paddle was rotated. The results were interpreted as negative (-), trace (T), weak positive (1), distinct positive (2), and strong positive (3).

\section{WST}

Fifty microliters (five drops) of milk were placed on a glass slide with a blue background. Subsequently, $20 \mu \mathrm{L}$ (two drops) of 4\% sodium hydroxide $(\mathrm{NaOH})$ solution was added to the milk sample and the mixture was stirred rapidly with a toothpick for 20-25 s. The results were interpreted as strong $(+++)$, distinct $(++)$, weak $(+)$, trace $( \pm)$, and negative $(-)$ based on the formation of coagulation.

\section{SFMT}

A shallow paddle having four cups was used and rinsed after each use. About $2 \mathrm{~mL}$ of milk sample and equal volume of 3\% SFMT reagent (Surf Excel ${ }^{\circledR}$ Unilever, Bangladesh) was mixed in the cup of a paddle. Mixing was accomplished by gentle circular motion of the paddle in horizontal position for few seconds. The formation of gel indicated that the sample was positive for SCM. The peak of reaction was obtained within $30 \mathrm{~s}$. The results were interpreted based on the gel formation as negative $(-)$, trace $( \pm)$, weak reaction $(+)$, moderate reaction $(++)$, and strong reaction $(+++)$. For all the indirect screening tests, milk samples giving weak to strong reactions were considered positive for SCM.

\section{SCC}

Fifty microliters of milk sample and an equal volume of reagent $\mathrm{C}$ (1:1 dilution) were taken in an Eppendorf tube using micropipette and mixed using a vortex mixture. Then, SCC-Cassette was loaded with the diluted milk sample by immersing the tip of the cassette into the solution and pressing the piston. The SCCCassette was placed in the instrument (NucleoCounter ${ }^{\circledR}$ SCC-100, Chemometec, Denmark) and pressed the "Run" key. After $30 \mathrm{~s}$, the SCC was presented on the instrument display. A milk sample was considered positive when the SCC value was $\geq 100 \times 10^{3}$ cells $/ \mathrm{mL}$ [32]

\section{Anionic surfactant as test solution to detect SCM in dairy cows}

SLS was selected as a test reagent for the diagnosis of SCM. Different concentrations of SLS were used with or without $\mathrm{NaOH}$ and indicators (bromothymol blue [BTB] and bromocresol purple [BCP]).

\section{Test procedure}

An equal volume $(1 \mathrm{~mL})$ of SLS solutions and milk sample was mixed on a shallow paddle having four cups, and the mixing was properly done by the gentle circular motion of the paddle for few seconds. The reaction developed almost immediately with milk containing a high concentration of somatic cells. The peak of reaction was obtained within $10 \mathrm{~s}$ and any change in the milk, such as viscosity, consistency was observed as mentioned below.

\begin{tabular}{|c|c|c|}
\hline Reaction characteristics & Score & Infection \\
\hline $\begin{array}{l}\text { Consistency and viscosity } \\
\text { are normal. }\end{array}$ & $\begin{array}{l}\text { Negative } \\
(0)\end{array}$ & int \\
\hline $\begin{array}{l}\text { Very slight thread formation } \\
\text { and/or precipitation } \\
\text { disappearing after stirring }\end{array}$ & Trace $( \pm)$ & $\begin{array}{l}\text { Slight infection } \\
\text { risk }\end{array}$ \\
\hline $\begin{array}{l}\text { Distinct precipitation and } \\
\text { threads formation but no } \\
\text { gel formation }\end{array}$ & $\begin{array}{l}\text { Weak } \\
\text { positive }(+)\end{array}$ & $\begin{array}{l}\text { Subclinical } \\
\text { mastitis }\end{array}$ \\
\hline $\begin{array}{l}\text { Mixture become } \\
\text { more viscous and } \\
\text { formation of gel }\end{array}$ & $\begin{array}{l}\text { Distinct } \\
\text { positive } \\
(++)\end{array}$ & $\begin{array}{l}\text { Subclinical } \\
\text { mastitis }\end{array}$ \\
\hline $\begin{array}{l}\text { Distinct gel formation, which } \\
\text { is thick and has tendency to } \\
\text { adhere to the bottom of the } \\
\text { cup of the paddle }\end{array}$ & $\begin{array}{l}\text { Strong } \\
\text { positive } \\
(+++)\end{array}$ & $\begin{array}{l}\text { Subclinical } \\
\text { mastitis near } \\
\text { the clinical } \\
\text { stage }\end{array}$ \\
\hline
\end{tabular}

\section{Statistical analysis}

SCC was considered as the gold standard test for the determination of epidemiological test characteristics of different indirect screening tests as well as test anionic surfactant - SLS. Five quality parameters: $S e, S p$, positive predictive value (PPV), negative predictive value (NPV), and kappa-value were calculated. The results were weighted on the basis of kappa value, which ranges from 1 to -1 , where a value of -1 indicates complete disagreement between tests, 0 indicates agreement by chance only, 0.01-0.20 indicates slight agreement, 0.21-0.40 indicates a fair amount of agreement, 0.41-0.60 indicates moderate agreement, 0.61-0.80 indicates substantial agreement, and 0.81-1 indicates almost perfect agreement [33]. The SPSS v.20 was used for all the analyses.

\section{Receiver operating characteristic (ROC) curve}

A graph of $S e$ against $1-S p$, that is, a ROC curve was generated and the performance of a diagnostic test was quantified by calculating the area under the ROC curve (AUROC). The ideal test would have an AUROC of 1 .

\section{Results}

Comparison of existing indirect screening tests with SCC

Four popularly used indirect screening tests (Leucocytest, WST, SFMT, and Immucell) along with SCC as gold standard test were employed on 106 milk samples of dairy cows to diagnose SCM and to compare the test characteristics. Leucocytest had comparatively higher $\mathrm{Se}(64.9 \%)$ than that of WST $(45.9 \%)$, Immucell (56.8\%), and SFMT (63.9\%) (Table-1). Kappa-value indicated substantial agreement of Leucocytest with SCC. Therefore, Leucocytest was selected for further comparison with test anionic surfactant SLS. 


\section{Evaluation of SLS at different concentrations}

SLS with or without $\mathrm{NaOH}$ yielded the best reaction with the milk samples similar to Leucocytest. It was observed that the reaction of milk samples with SLS added with indicators (BTB and BCP) was easier to visualize than without indicators. $S e, S p$ and kappa-value of SLS 3\%+NaOH $1.5 \%$ with BTB and SLS $2 \%$ with BCP were higher than other concentrations of SLS (Table-2). The Se and $S p$ of both Leucocytest and $2 \%$ SLS with BCP was 1 , and the area under the curve (AUROC) for both the tests was 0.917, which was higher than AUROC of other concentrations of SLS (Figure-1). The AUROC of 3\% SLS $+1.5 \% \mathrm{NaOH}$ with BTB was also high (0.875). As SLS 3\%+NaOH $1.5 \%$ with BTB and SLS $2 \%$ with BCP gave the best reactions in terms of $S e, S p$ and diagnostic agreement they can be potential reagents to be used as indirect screening tests to diagnose SCM in dairy cows. The test results are further summarized in Table-3.

\section{Discussion}

SCM is not a problem of individual cows rather a problem at the dairy herd level; therefore, it is essential to test the dairy cows of the herd periodically for the screening of SCM [6]. Se and $S p$ are intrinsic values of a test and are useful for comparing one diagnostic test with another [34]. However, they cannot be used to determine the probability that a given test result reflects the true disease status of the animal [35]. Se and $S p$ can be calculated only if there is an objective, independent means of determining whether the disease is truly present [34].

Here, an anionic surfactant, SLS was evaluated based on the Se and Sp taking SCC as the gold standard for the detection of SCM in dairy cows. SLS with or without $\mathrm{NaOH}$ at different concentrations gave better reaction with the milk samples similar to existing indirect screening test, Leucocytest. SLS decreases surface tension, change the structure and conductivity of cell membrane and nucleus, interfere osmotic balance, block oxidization and stimulate proteolytic enzymes, and increases milk viscosity. $\mathrm{NaOH}$ degrades somatic cells; as a result, the DNA of the cells reacts with the solution and forms gel, which indicates the presence of SCM. Earlier, SLS was evaluated to be used as CMT substitute; however, the test properties and interpretation of results were not clearly explained [16,29]. The high $\mathrm{Se}$ of a test indicates the proportion of total infected quarters that are truly infected. The Se of SLS solutions was very much close and similar to the Leucocytest. It was also observed that the $S p$ of the SLS solutions was also high, which means that it is able to detect uninfected samples which are not truly infected. These highly satisfactory intrinsic values of the SLS solutions increased the acceptability of this solution to be used as a test solution to detect SCM in dairy cows.

In addition, PPV and NPV were also high, which indicates that SLS identified milk samples from truly affected quarters as positive and from truly not-affected quarters as negative. Further evaluation was done by adding indicators to SLS to observe the reaction of milk. Indicator is a halochromic chemical compound added in small amounts to a solution so that the reaction of the solution can be determined visually $[36,37]$. Therefore, SLS with or without $\mathrm{NaOH}$

Table-1: Sensitivity, specificity, and agreement of four indirect screening tests with somatic cell count for the diagnosis of subclinical mastitis $(n=106)$.

\begin{tabular}{lccccc}
\hline $\begin{array}{l}\text { Screening } \\
\text { tests }\end{array}$ & $\begin{array}{c}\text { Se } \\
\text { \% }\end{array}$ & $\begin{array}{c}\text { Sp } \\
\text { \% }\end{array}$ & $\begin{array}{c}\text { PPV } \\
\text { \% }\end{array}$ & $\begin{array}{c}\text { NPV } \\
\text { \% }\end{array}$ & $\begin{array}{c}\text { Kappa- } \\
\text { value }\end{array}$ \\
\hline WST & 45.9 & 98.6 & 97.4 & 77.5 & 0.505 \\
SFMT & 63.9 & 85.1 & 69.7 & 81.4 & 0.499 \\
Leukocytes & 64.9 & 95.7 & 92.5 & 84.1 & 0.646 \\
ImmuCell & 56.8 & 80.8 & 80.4 & 81.0 & 0.455 \\
\hline
\end{tabular}

$\mathrm{n}=$ Number of milk samples, $\mathrm{WST}=$ White side test, $\mathrm{SFMT}=$ Surf field mastitis test, $\mathrm{Se}=$ Sensitivity, $\mathrm{Sp}=$ Specificity, PPV=Positive predictive value, $\mathrm{NPV}=$ Negative predictive value, Kappavalue $=$ Measurement of agreement

Table-2: Sensitivity, specificity, and agreement of sodium lauryl sulfate with and without indicators with somatic cell count for the diagnosis of subclinical mastitis $(n=273)$.

\begin{tabular}{lccccc}
\hline Screening tests & $\begin{array}{c}\text { Se } \\
\%\end{array}$ & $\begin{array}{c}\text { Sp } \\
\text { \% }\end{array}$ & $\begin{array}{c}\text { PPV } \\
\text { \% }\end{array}$ & $\begin{array}{c}\text { NPV } \\
\text { \% }\end{array}$ & $\begin{array}{c}\text { kappa- } \\
\text { value }\end{array}$ \\
\hline SLS 3\% & 77.8 & 91.7 & 93.3 & 73.3 & 0.667 \\
SLS 3\% with BTB & 61.1 & 100 & 100 & 63.1 & 0.557 \\
SLS 3\%+NaOH 1.5\% & 83.3 & 91.7 & 93.7 & 78.6 & 0.730 \\
SLS 3\%+NaOH 1.5\% & 83.3 & 91.7 & 93.7 & 78.6 & 0.730 \\
with BTB & & & & & \\
SLS 2\% & 66.7 & 100 & 100 & 66.7 & 0.615 \\
SLS 2\% with BTB & 77.8 & 83.3 & 87.5 & 71.4 & 0.595 \\
SLS 2\% with BCP & 100 & 83.3 & 90 & 100 & 0.857 \\
SLS 2\%+NaOH 1.5\% & 72.2 & 100 & 100 & 70.6 & 0.675 \\
SLS 2\%+NaOH 1.5\% & 77.8 & 91.7 & 93.3 & 73.3 & 0.667 \\
with BTB & & & & & \\
SLS 2\%+NaOH 1.5\% & 72.2 & 83.3 & 86.7 & 66.7 & 0.533 \\
with BCP & & & & & \\
Leukocytes & 100 & 83.3 & 90 & 100 & 0.857 \\
\hline
\end{tabular}

$\mathrm{n}=$ Number of milk samples, $\mathrm{SLS}=$ Sodium lauryl sulphate, $\mathrm{BTB}=$ Bromothymol blue, $\mathrm{NaOH}=$ Sodium hydroxide, $\mathrm{BCP}=$ Bromocresol purple, Se=Sensitivity, $S p=$ Specificity, $\mathrm{PPV}=$ Positive predictive value, NPV $=$ Negative predictive value, Kappa-value $=$ Measurement of agreement

Table-3: Sensitivity, specificity, and agreement of sodium lauryl sulfate with indicators with somatic cell count for the diagnosis of subclinical mastitis.

\begin{tabular}{lccccc}
\hline Screening test & \multicolumn{5}{c}{ SCC } \\
\cline { 2 - 6 } & $\begin{array}{r}\text { Se } \\
\text { \% }\end{array}$ & $\begin{array}{c}\text { Sp } \\
\text { \% }\end{array}$ & $\begin{array}{c}\text { PPV } \\
\%\end{array}$ & $\begin{array}{c}\text { NPV } \\
\%\end{array}$ & $\begin{array}{c}\text { kappa- } \\
\text { value }\end{array}$ \\
\hline SLS 3\%+NaOH & 83.3 & 91.7 & 93.7 & 78.6 & 0.730 \\
1.5\% with BTB & & & & & \\
SLS 2\% with BCP & 100 & 83.3 & 90 & 100 & 0.857 \\
Leukocytes & 100 & 83.3 & 90 & 100 & 0.857 \\
\hline
\end{tabular}

SLS=Sodium lauryl sulfate, BTB=Bromothymol blue, $\mathrm{NaOH}=$ Sodium hydroxide, $\mathrm{BCP}=$ Bromo cresol purple, $\mathrm{Se}=$ Sensitivity, $\mathrm{S} p=$ Specificity, $\mathrm{PPV}=$ Positive predictive value, NPV $=$ Negative predictive value, Kappavalue $=$ Measurement of agreement 


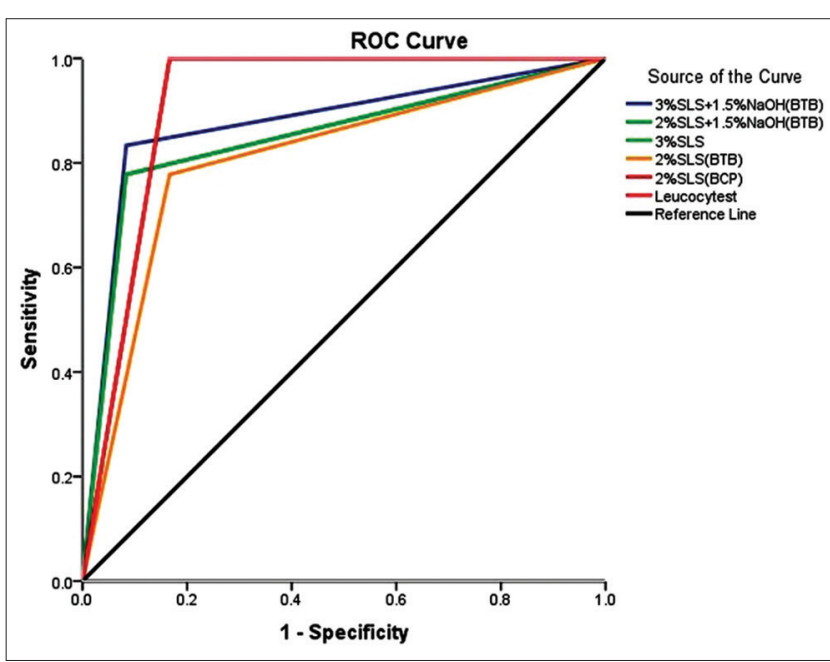

Figure-1: Receiver operating characteristic curve for different tests performance.

were subjected to further evaluation with or without indicators (BTB and BCP). It was observed that the reaction of milk samples with SLS added with indicators (BTB and BCP) was easier to visualize than without indicators. $S e, S p$ and kappa-value of SLS $3 \%+\mathrm{NaOH} 1.5 \%$ with BTB and SLS $2 \%$ with BCP were higher than other concentrations of SLS. Among the available screening tests, the $S e$ was very low in case of WST and SFMT. Muhammad et al. [24], Sarker [38], and Badiuzzaman et al. [25] also reported the lower Se of WST and SFMT. Although Leucocytest had high $S e$ and $S p$ it is somewhat costly as well as not readily available whenever needed in our country. On the other hand, WST and SFMT are not appreciated due to its low Se.

\section{Conclusion}

SLS $3 \%+\mathrm{NaOH} 1.5 \%$ with BTB and SLS $2 \%$ with BCP may be the potential reagents to be used as test solutions to detect SCM in dairy cows as SLS is available and relatively cheap in our country. However, field evaluation of these reagents is needed to validate their characteristics as a screening test to detect SCM in dairy cows.

\section{Authors' Contributions}

NST and MTI: Conceptualization. NST, MSI, and MK: Sample collection, data collection, and data curation. NST, MSI, MK, and MSP: Formal analysis. MTI: Funding acquisition. NST: Investigation. NST: Methodology. MTI and MAE: Project administration. NST, MSP, and MTI: Resources. MTI and MAE: Supervision. NST, MSP, and MTI: Validation and visualization. NST: Writing - original draft. NST, MSI, MK, MSP, MAE, and MTI: Writing - review and editing. All authors read and approved the final manuscript.

\section{Acknowledgments}

The research was financially supported by the Bangladesh Agricultural University Research System
(Grant No. 2017/237/BAU). We gratefully thank the smallholder dairy farmers for their generous support during the collection of milk samples.

\section{Competing Interests}

The authors declare that they have no competing interests.

\section{Publisher's Note}

Veterinary World remains neutral with regard to jurisdictional claims in published institutional affiliation.

\section{References}

1. Constable, P.D., Hinchcliff, K.W., Done, S.H. and Grünberg, W. (2017) Veterinary Medicine. $11^{\text {th }}$ ed. Saunders Ltd., United States.

2. Busanello, M., Rossi, R.S., Cassoli, L.D., Pantoja, J.C. and Machado, P.F. (2017) Estimation of prevalence and incidence of subclinical mastitis in a large population of Brazilian dairy herds. J. Dairy Sci., 100(8): 6545-6553.

3. Hiitiö, H., Vakkamäki, J., Simojoki, H., Autio, T., Junnila, J., Pelkonen, S. and Pyörälä, S. (2017) Prevalence of subclinical mastitis in Finnish dairy cows: Changes during recent decades and impact of cow and herd factors. Acta Vet. Scand., 59(1): 22.

4. Kumari, T., Bhakat, C. and Choudhary, R.K. (2018) A review on subclinical mastitis in dairy cattle. Int. J. Pure Appl. Biosci., 6(2): 1291-1299.

5. Guimarães, J.L., Brito, M.A., Lange, C.C., Silva, M.R., Ribeiro, J.B., Mendonça, L.C., Mendonça, J.F. and Souza, G.N. (2017) Estimate of the economic impact of mastitis: A case study in a Holstein dairy herd under tropical conditions. Prev. Vet. Med., 142: 46-50.

6. Aghamohammadi, M., Haine, D., Kelton, D.F., Barkema, H.W., Hogeveen, H., Keefe, G.P. and Dufour, S. (2018) Herd-level mastitis-associated costs on Canadian dairy farms. Front. Vet. Sci., 5: 100.

7. Kader, M., Samad, M. and Saha, S. (2003) Influence of host level factors on prevalence and economics of subclinical mastitis in dairy milch cows in Bangladesh. Indian J. Dairy Sci., 56(4): 235-240.

8. Seegers, H., Fourichon, C. and Beaudeau, F. (2003) Production effects related to mastitis and mastitis economics in dairy cattle herds. Vet. Res., 34(5): 475-491.

9. Cobirka M., Tancin V., Slama P. (2020) Epidemiology and Classification of Mastitis. Animals, 10(12): 2212.

10. Mungube, E., Tenhagen, B.A., Regassa, F., Kyule, M., Shiferaw, Y., Kassa, T. and Baumann, M. (2005) Reduced milk production in udder quarters with subclinical mastitis and associated economic losses in crossbred dairy cows in Ethiopia. Trop. Anim. Health Prod., 37(6): 503-512.

11. Romero, J., Benavides, E. and Meza, C. (2018) Assessing financial impacts of subclinical mastitis on Colombian dairy farms. Front. Vet. Sci., 5: 273.

12. Schepers, J. and Dijkhuizen, A. (1991) The economics of mastitis and mastitis control in dairy cattle: A critical analysis of estimates published since 1970. Prev. Vet. Med., 10(3): 213-224.

13. Sarker, S.C., Parvin, M.S., Rahman, A.A. and Islam, M.T. (2013) Prevalence and risk factors of subclinical mastitis in lactating dairy cows in North and South Regions of Bangladesh. Trop. Anim. Health Prod., 45(5): 1171-1176.

14. Sumon, S., Ehsan, M. and Islam, M. (2017) Subclinical mastitis in dairy cows: Somatic cell counts and associated bacteria in Mymensingh, Bangladesh. J. Bangladesh Agric. Univ., 15(2): 266-271.

15. Ruegg, P.L. (2017) A 100-year review: Mastitis detection, management, and prevention. J. Dairy Sci., 100(12): 
10381-10397.

16. Sharma, N., Pandey, V. and Sudhan, N. (2010) Comparison of some indirect screening tests for detection of subclinical mastitis in dairy cows. Bulg. J. Vet. Med., 13(2): 98-103.

17. Dohoo, I., Smith, J., Andersen, S., Kelton, D. and Godden, S. (2011) Diagnosing intramammary infections: Evaluation of definitions based on a single milk sample. J. Dairy Sci., 94(1): 250-261.

18. Sharma, N., Singh, N. and Bhadwal, M. (2011) Relationship of somatic cell count and mastitis: An overview. Asian Australas. J. Anim. Sci., 24(3): 429-438.

19. Schwarz, D., Santschi, D.E., Durocher, J. and Lefebvre, D.M. (2020) Evaluation of the new differential somatic cell count parameter as a rapid and inexpensive supplementary tool for udder health management through regular milk recording. Prev. Vet. Med., 181: 105079.

20. Petzer, I.M., Karzis, J., Donkin, E.F., Webb, E.C. and Etter, E. (2017) Somatic cell count thresholds in composite and quarter milk samples as indicator of bovine intramammary infection status. Onderstepoort J. Vet. Res., 84(1): e1-10.

21. Lipkens, Z., Piepers, S., De Visscher, A. and De Vliegher, S. (2019) Evaluation of test-day milk somatic cell count information to predict intramammary infection with major pathogens in dairy cattle at drying off. J. Dairy Sci., 102(5): 4309-4321.

22. Dalen, G., Rachah, A., Nørstebø, H., Schukken, Y.H. and, O. (2019) The detection of intramammary infections using online somatic cell counts. J. Dairy Sci., 102(6): 5419-5429.

23. Deng, Z., Hogeveen, H., Lam, T.J., Van Der Tol, R. and Koop, G. (2020) Performance of online somatic cell count estimation in automatic milking systems. Front. Vet. Sci., 7: 221 .

24. Muhammad, G., Naureen, A., Asi, M.N. and Saqib, M. (2010) Evaluation of a 3\% surf solution (surf field mastitis test) for the diagnosis of subclinical bovine and bubaline mastitis. Trop. Anim. Health Prod., 42(3): 457-464.

25. Badiuzzaman, M., Samad, M., Siddiki, S., Islam, M. and Saha, S. (2016) Subclinical mastitis in lactating cows: Comparison of four screening tests and effect of animal factors on its occurrence. Bangladesh J. Vet. Med., 13(2): 41-50.

26. Viani, M., Filho, A.N., Rossetti, D., Longhi, J. and Sicher, M. (1990) Efficiency of the CMT in estimating the number of somatic cell count in buffaloes. Ciênc. Vet. J., 4(3): 3-4.

27. Godden, S., Royster, E., Timmerman, J., Rapnicki, P. and Green, H. (2017) Evaluation of an automated milk leukocyte differential test and the California Mastitis Test for detecting intramammary infection in early-and late-lactation quarters and cows. J. Dairy Sci., 100(8): 6527-6544.

28. Neelesh, S., Maiti, S., Vijay, P. (2008) Sensitivity of indirect tests in the detection of sub-clinical mastitis in buffaloes. Vet. Pract., 9(1): 29-31.

29. Sudhan, N., Singh, R., Singh, M. and Soodan, J. (2005) Studies on prevalence, etiology and diagnosis of subclinical mastitis among crossbred cows. Indian J. Anim. Res., 39(2): 127-130.

30. Middleton, J.R., Hardin, D., Steevens, B., Randle, R. and Tyler, J.W. (2004) Use of somatic cell counts and California mastitis test results from individual quarter milk samples to detect subclinical intramammary infection in dairy cattle from a herd with a high bulk tank somatic cell count. J. Am. Vet. Med. Assoc., 224(3): 419-423.

31. Pandit, A. and Mehta, M. (1969) Sodium lauryl sulphate as a substitute for CMT reagent (California Mastitis test Reagent) for diagnosis of subclinical mastitis in buffaloes. Indian Vet. J., 46: 111-119.

32. Sumon, S.M.R., Parvin, M.S., Ehsan, M.A. and Islam, M.T. (2020) Relationship between somatic cell counts and subclinical mastitis in lactating dairy cows. Vet. World, 13(8): 1709-1713.

33. Landis, J.R. and Koch, G.G. (1977) The measurement of observer agreement for categorical data. Biometrics, 33(1): 159-174.

34. Kivaria, F., Noordhuizen, J. and Nielen, M. (2007) Interpretation of California mastitis test scores using Staphylococcus aureus culture results for screening of subclinical mastitis in low yielding smallholder dairy cows in the Dar es Salaam region of Tanzania. Prev. Vet. Med., 78(34): 274-285.

35. Greiner, M. and Gardner, I. (2000) Epidemiologic issues in the validation of veterinary diagnostic tests. Prev. Vet. Med., 45(1-2): 3-22.

36. Crofts, A. and Jackson, J. (1969) Bromothymol blue and bromocresol purple as indicators of $\mathrm{pH}$ changes in chromatophores of Rhodospirillum rubrum. FEBS J., 10(1969): 226-237.

37. Al-Husseini, Z.N.O. (2019) A literature review on the indicators in precipitation. Am. Int. J. Sci. Eng. Res., 2(1): 1-8.

38. Sarker, S.C. (2011) Subclinical Mastitis in Dairy Cows: Identification of Risk Factors and Comparison of Three Screening Tests. An MS Thesis Submitted to Department of Medicine. Bangladesh Agricultural University, Mymensingh. p1-34. 